\title{
BMJ Open Trends in diagnosis-specific work disability before and after ischaemic heart disease: a nationwide population- based cohort study in Sweden
}

\author{
Jenni Ervasti, ${ }^{1}$ Marianna Virtanen, ${ }^{1,2}$ Tea Lallukka, ${ }^{1,3}$ Emilie Friberg, ${ }^{4}$ \\ Ellenor Mittendorfer-Rutz, ${ }^{4}$ Erik Lundström, ${ }^{5}$ Kristina Alexanderson ${ }^{4}$
}

To cite: Ervasti J, Virtanen M, Lallukka T, et al. Trends in diagnosis-specific work disability before and after ischaemic heart disease: a nationwide populationbased cohort study in Sweden. BMJ Open 2018;8:e019749. doi:10.1136/ bmjopen-2017-019749

- Prepublication history and additional material for this paper are available online. To view these files, please visit the journal online (http://dx.doi org/10.1136/bmjopen-2017019749).

Received 22 September 2017 Revised 15 February 2018 Accepted 20 February 2018

Check for updates

${ }^{1}$ Finnish Institute of Occupational Health, Helsinki, Finland ${ }^{2}$ Department of Public Health and Caring Sciences, University of Uppsala, Uppsala, Sweden

${ }^{3}$ Faculty of Medicine, University of Helsinki, Helsinki, Finland

${ }^{4}$ Division of Insurance Medicine, Department of Clinical Neuroscience, Karolinska Institutet, Stockholm, Sweden

${ }^{5}$ Division of Neurology,

Department of Clinical

Neuroscience, Karolinska

Institutet, Stockholm, Sweden

Correspondence to

Dr Jenni Ervasti;

jenni.ervasti@ttl.fi

\section{ABSTRACT}

Objectives We examined trends of diagnosis-specific work disability before and after ischaemic heart disease (IHD).

Design Participants were followed 4 years before and 4 years after an IHD event for diagnosis-specific work disability (sickness absence and disability pension). Setting and participants A Swedish population-based cohort study using register data on all individuals aged 25-60 years, living in Sweden, and who suffered their first IHD event in 2006-2008 ( $n=23$ 971) was conducted.

Results Before the event, the most common diagnoses of work disability were musculoskeletal disorders (21 annual days for men and 44 for women) and mental disorders (19 men and 31 for women). After multivariable adjustments, we observed a fivefold increase (from 12 to 60 days) in work disability due to diseases of the circulatory system in the first postevent year compared with the last preevent year among men. Among women, the corresponding increase was fourfold (from 14 to 62 days). By the second postevent year, the number of work disability days decreased significantly compared with the first postevent year among both sexes (to 19 days among men and 23 days among women). Among women, mean days of work disability due to diseases of the circulatory system remained at a higher level than among men during the postevent years. Work disability risk after versus before an IHD event was slightly higher among men (rate ratio (RR) 2.49; $95 \% \mathrm{Cl} 2.36$ to 2.62) than among women (RR 2.29, $95 \% \mathrm{Cl} 2.12$ to 2.49 ). When pre-event long-term work disability was excluded, diseases of the circulatory system were the most prevalent diagnosis for work disability after an IHD event among both men and women.

Conclusions An IHD event was strongly associated with an increase in work disability due to diseases of the circulatory system, especially among men and particularly in the first postevent year.

\section{INTRODUCTION}

The risk of ischaemic heart disease (IHD) increases from the age of 45 among men and 55 among women. ${ }^{12}$ Thus, the onset of IHD is often at working age, and it has been linked with a high risk of work disability
Strengths and limitations of this study

- This is the first nationwide population-based study on diagnoses of work disability (sickness absence and disability pension) before and after ischaemic heart disease (IHD) event.

- Data were from reliable register-based measurements of high coverage and specificity, and no loss to follow-up.

- Monitoring the sickness absence patterns and trajectories of patients after their IHD event may help to prevent permanent exit from the labour market.

- While we could include many confounders related to sociodemographic characteristics and treatment procedures, register data also have their limitations; we had no information on traditional cardiovascular risk factors, psychosocial work environment, nor information on quality and outcome of postevent care.

(sickness absence and disability pension). ${ }^{3-7}$ In Sweden, the estimated productivity losses and indirect costs of myocardial infarction were estimated to be 25 days, corresponding to indirect costs of $€ 3465$ per event during the year following the event. ${ }^{6}$ In addition to productivity losses, the direct medical costs of IHD are substantial. ${ }^{89}$

Comorbid conditions pose an additional risk to work ability: people with IHD and comorbid diabetes, mental disorders or musculoskeletal disorders are at a higher risk of work disability than those without these comorbid conditions. ${ }^{10-13}$ Alternatively, it is possible that other diseases, particularly depression and other common mental disorders, are more likely to occur after an IHD event than if no such event has occurred. ${ }^{1415}$ This would, in turn, increase mental disorder-related work disability after an IHD event. These findings highlight the important role of comorbidity in relation to work disability among people with IHD. However, the causes of work disability before and after an IHD 
event remain unknown. Knowledge about the trends of diagnosis-specific work disability among people with IHD can be beneficial when planning specific interventions to promote the resumption of economic activity.

IHD manifests differently among women than among men, including clinical presentation, importance of particular risk factors, pathophysiology of disease and treatments/outcomes. ${ }^{16}{ }^{17}$ While women are more at risk of work disability after an IHD event, ${ }^{10-12} 18$ coronary heart disease is generally more common and more fatal among working-aged men. ${ }^{19}$ Previous research has also suggested that sickness absence due to circulatory diseases may be a stronger predictor of death among men than among women. ${ }^{20}$ Thus, our aim was to investigate the trends of diagnosis-specific work disability, as indicated by sickness absence and disability pension, 4 years before and 4 years after an IHD event among men and women living in Sweden.

\section{MATERIAL AND METHODS}

This cohort study was based on Insurance Medicine All Sweden research database, which is an individual-level register-linkage data covering about 12 million people over several decades nationwide. The population of Sweden in 2006-2008 was about 9.1-9.2 million, of whom $61 \%$ were aged 18-64 (in 2010) corresponding to about 5.5 million people. ${ }^{21}$ The study cohort consisted of all people living in Sweden, who at the event date in 2006, 2007 or 2008 were aged 25-60 years, had been living in Sweden for 5 years before the event and had no indication of IHD between 2001 and the event date. First event dates were included for all cases, except for cases in which death occurred within 30 days of the event, resulting in a sample of 23971 cases. Thus, our study cohort with new-onset IHD in 2006-2008 represents roughly $0.5 \%$ of the same-aged population of Sweden.

An IHD event was based on hospitalisation or specialised outpatient care for myocardial infarction or other IHD, excluding angina pectoris (ie, codes I21-I25 were included). The follow-up begun from the event date $\left(\mathrm{T}_{0}\right)$ and continued for 4 years $\left(\mathrm{T}_{1}\right.$ to $\left.\mathrm{T}_{4}\right)$. Before-event data were gathered 4 years prior to the event date $\left(\mathrm{T}_{-4}\right.$ to $\left.\mathrm{T}_{-1}\right)$. The participants had to have survived until the event and 30 days after the event, but not necessarily thereafter. A total of 1184 deaths $(5 \%)$ were observed during the four postevent years.

Data were obtained from several nationwide registers and linked with personal identity numbers. The following registers were used:

1. Statistics Sweden: Longitudinal Integration Database for Health Insurance and Labour Market Studies regarding sex, age, education, family situation, place of birth, type of living area and labour market activity.

2. National Board of Health and Welfare: Patient register: diagnosis-specific data on hospitalisations and specialised outpatient care (coded according to the International Classification of Diseases, 10th revision
(ICD-10, WHO, 1994); medical treatment procedures; cancer register; date of death.

3. National Social Insurance Agency: information on sickness absence and disability pension benefits.

\section{Outcome: diagnosis-specific work disability}

Work disability was defined as days of annual sickness absence or disability pension, as indicated by sick leave and disability pension benefits. In Sweden, all people with income from work or unemployment benefits with reduced work capacity due to disease or injury are entitled to sick leave benefit. The treating physician evaluates whether the patient has a disease or injury and whether this condition impairs work capacity to the extent that the person is unable to work. In most cases, the first 14 days of sick leave are covered by the employer and thus not registered by the Social Insurance Agency. All individuals, including those with no previous income, can be granted disability pension if their work capacity is permanently reduced owing to the disease or injury.

We examined the following ICD-10 diagnostic groups: neoplasms (C00-D48); diabetes (E10-E14); other endocrine, nutritional and metabolic diseases (E00-E09, E15-E90); mental disorders (F00-F99); diseases of the nervous system (G00-G99); diseases of the circulatory system (I00-I99); diseases of the respiratory system (J00J99); diseases of the digestive system (K00-K93); diseases of the skin and subcutaneous tissue (L00-L99); musculoskeletal disorders (M00-M99) and injuries (S00-T35, T66-T78, T79). Diagnostic groups of A, B, H, N, O, P, Q, $\mathrm{R}, \mathrm{V}, \mathrm{Y}, \mathrm{Z}$ and $\mathrm{U}$ were not studied due to their infrequency in our cohort.

\section{Confounding factors}

Known risk factors for sickness absence and disability pension, that is, older age (continuous variable), lower education ('low' <10 years; 'intermediate' 10-12 years (high school); 'high' $>12$ years (college/university)), economic activity ('in paid work'; 'not in paid work': unemployed, student, on parental leave, etc), not being married (family situation: 'married/cohabitant'; 'not married/cohabitant, no children' (single); 'not married/cohabitant with children' (single parent)), living in smaller towns (large city'; 'medium-sized town'; 'small town/village'), and being born outside Sweden ('Sweden'; 'Other') were treated as possible confounders. All confounders were measured at the event.

Having undergone an IHD-related medical treatment procedure was considered a proxy for a more severe event, and was also treated as a possible confounder. Medical treatment procedures were coded according to Nordic Medico-Statistical Committee Classification of Surgical Procedures. ${ }^{22}$ Procedures were registered during the year before the event $\left(T_{-1}\right)$ or the year after the event $\left(T_{1}\right)$, and included coronary artery bypass graft (FNA-FNE, FNH 20), percutaneous coronary intervention (FNG 02, FNG $05)$ and other coronary surgeries (FNF, FNG 00, FNG 10, FNG 20, FGN 22, FNG 30, FNG 96). Individuals with at 
least one such procedure were coded as 'yes' and those without as 'no'.

\section{Statistical analysis}

Differences between men and women were tested using $\chi^{2}$ tests except for continuous variable age, for which one-way analysis of variance was used. We used the repeated measures negative binomial regression procedure and the generalised estimating equations method to produce least square means and rate ratios (RRs) and their 95\% CIs to estimate trends and risk of diagnosis-specific work disability before and after an IHD event, except for work disability due to diseases of the circulatory system (I00I99), where the estimates were produced using Poisson distribution due to conversion problems with negative binomial distribution. This method considers the intraindividual correlation between measurements.

To demonstrate the absolute levels of diagnosis-specific work disability, annual means of work disability were calculated for each diagnostic group for 4 years before and 4 years after the IHD event. As a supplementary analysisto express the difference in the shape of the trajectory of work disability - we calculated the RRs per 4 years in work disability separately for the pre-event (years -4 to -1 ) and postevent (years 1-4) periods. RRs above 1 suggest an increasing trend, and RRs below 1 suggest a decreasing trend. These estimates (shown in online supplementary table 1) help to confirm whether changes in mean annual work disability days are statistically significant.

To express the relative risk of work disability in the main diagnostic groups (circulatory, musculoskeletal, mental and diabetes) during the years after the IHD diagnosis in relation to the years before the diagnosis, we calculated RR and their 95\% CI by contrasting the 4-year window after diagnosis (years 1-4) with the 4-year window before the diagnosis (years -4 to -1 ) adjusting for age, sex, education, type of living area, family situation, birth country, economic activity and medical treatment procedures at diagnosis. Moreover, we examined whether sex modified the risk of work disability in time by entering interaction term (sexxyear) into the adjusted regression models. Year was entered as a categorical variable in the analyses. These analyses produced least square means. Their exponential functions were used to obtain adjusted annual means to demonstrate the adjusted absolute levels of work disability. The SAS V.9.4 was used for all analysis (SAS Institute).

If a person is permanently work disabled due to, for example, musculoskeletal disorders before the IHD event, this person remains on disability pension due to musculoskeletal disorders also after an IHD event. To control for these competing risks, and the fact that one person cannot be granted disability benefits for two different diseases simultaneously, we performed additional sensitivity analyses among a subcohort from which those on disability pension or long-term sickness absence ( $>730$ consecutive days) before the event were excluded. We excluded 2411 women and 3910 men. Thus, $41 \%$ of
Table 1 Characteristics of the study participants at the year of the ischaemic heart disease event

\begin{tabular}{lllc}
\hline & $\begin{array}{l}\text { Men } \\
(\mathbf{n = 1 8 0 2 0 )}\end{array}$ & $\begin{array}{l}\text { Women } \\
(\mathbf{n = 5 9 5 1 )}\end{array}$ & $\begin{array}{l}\text { P values for } \\
\text { difference }\end{array}$ \\
\hline $\begin{array}{l}\text { Mean age, years } \\
\text { Education }\end{array}$ & $53.4(5.9)$ & $53.1(6.3)$ & 0.001 \\
$\quad$ Low, \% & 29 & 27 & $<0.001$ \\
$\quad$ Intermediate, \% & 49 & 53 & \\
$\quad$ High, \% & 22 & 20 & \\
$\begin{array}{l}\text { Living area } \\
\text { Large city, \% }\end{array}$ & 32 & 31 & 0.63 \\
\hline $\begin{array}{l}\text { Medium-sized } \\
\text { town, \% }\end{array}$ & 35 & 36 & \\
$\begin{array}{l}\text { Small town/village, } \\
\text { \% }\end{array}$ & 33 & 33 & \\
\hline
\end{tabular}

Family situation

\begin{tabular}{|c|c|c|c|}
\hline $\begin{array}{l}\text { Married/cohabitant, } \\
\%\end{array}$ & 60 & 56 & $<0.001$ \\
\hline Single, \% & 36 & 32 & \\
\hline Single parent, \% & 4 & 12 & \\
\hline \multicolumn{4}{|l|}{ Birth country } \\
\hline Sweden, \% & 80 & 81 & 0.10 \\
\hline Other, \% & 20 & 19 & \\
\hline \multicolumn{4}{|l|}{ Economic activity } \\
\hline Active, $\%$ & 75 & 64 & $<0.001$ \\
\hline Inactive, \% & 25 & 36 & \\
\hline \multicolumn{4}{|c|}{ Coronary artery bypass graft in $\mathrm{T}_{-1} / \mathrm{T}_{1}$} \\
\hline Yes, \% & 14 & 7 & $<0.001$ \\
\hline \multicolumn{4}{|c|}{ Percutaneous coronary intervention in $T_{-1} / T_{1}$} \\
\hline Yes, \% & 3.3 & 2.8 & 0.06 \\
\hline \multicolumn{4}{|c|}{ Other coronary surgeries in $T_{-1} / T_{1}$} \\
\hline Yes, \% & 0.1 & 0.2 & 0.34 \\
\hline
\end{tabular}

$\mathrm{T}-1$ and $\mathrm{T} 1$ refer to the year before and the year after the ischeamic heart disease event.

women and $22 \%$ of men were permanently disabled from work before the IHD event. These results are presented in online supplementary figures 1 and 2.

\section{RESULTS}

Of the study population with the first registered IHD diagnosis in 2006, 2007 or $2008(\mathrm{n}=23971), 75 \%$ were men and $25 \%$ were women (table 1 ). Single parenting was more prevalent among women, and being married or single without children was more common among men. More men were more often born elsewhere than in Sweden while more women were economically inactive. Of the medical procedures, more men than women had had coronary artery bypass graft.

Figure 1 shows the observed (unadjusted) trends in work disability 4 years before and 4 years after the event 


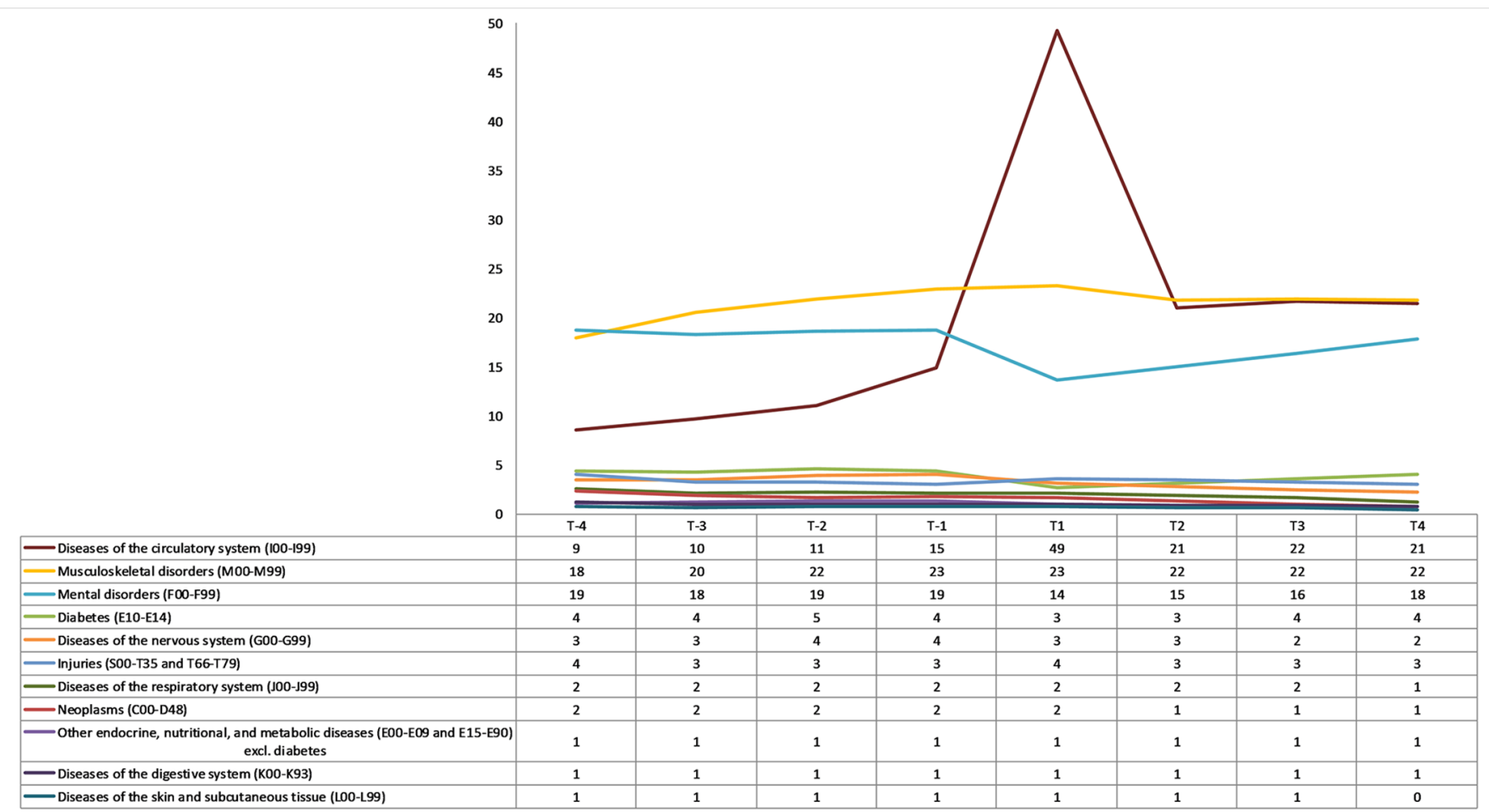

Figure 1 Mean annual number of days of work disability before and after an ischaemic heart disease event among men $(n=18020)$ by the International Classification of Diseases, 10th revision diagnostic category. T-4 to T4 refer to four years before and four years after the ischeamic heart disease event.

among men with an IHD event. Before the event, the most common reasons for work disability were mental and musculoskeletal disorders (about 20 annual absence days). Work disability due to diseases of the circulatory system strongly increased (from 15 to 49 days; 3.3-fold increase) the year after the event from the year before, diseases of the circulatory system being the most common reason for work disability in the first postevent year. The average number of work disability days due to diseases of the circulatory system decreased from the first postevent year to the second postevent year (from 49 days to 21 days; being only 0.42 times the level observed in the first postevent year). From the second postevent year onwards, work disability due to diseases of the circulatory system and musculoskeletal disorders was on the same level (about 20 annual work disability days), and circulatory system and musculoskeletal disorders were the two most common reasons for work disability, followed by mental disorders (15-18 annual absence days).

Figure 2 shows the corresponding trends for women. As for men, before the event, the two most common reasons for work disability among women were mental (about 30 annual absence days) and musculoskeletal (about 40 annual absence days) disorders. While there was also a sharp increase in work disability due to diseases of the circulatory system among women in the first postevent year (from 18 to 48 days; 2.7-fold increase) from the year before, musculoskeletal disorders remained the most common reason for work disability during the whole follow-up, with 39-49 annual absence days. In the first postevent year, diseases of the circulatory system (48 days) were as prevalent diagnoses for work disability as musculoskeletal disorders (49 days), but musculoskeletal (47 days) and mental (about 30 days) disorders were the leading diagnoses for work disability during the years after this. Among women, the average number of work disability days due to diseases of the circulatory system decreased from the first to the second postevent year by 23 days (being only 0.52 times the level observed in the first postevent year), and remained at the same level until the end of follow-up.

Online supplementary figures 1 and 2 show that when prior permanent work disability was excluded, diseases of the circulatory system were the most prevalent diagnosis of work disability after an IHD event among both men and women (men: $\mathrm{T}_{1}: 47$ days, $\mathrm{T}_{2}-\mathrm{T}_{4}: 12-13$ days; women $\mathrm{T}_{1}: 53$ days; $\mathrm{T}_{2}-\mathrm{T}_{4}: 17-18$ days). Postevent trend in work disability due to circulatory disease was rather similar in these sensitivity analyses than in the main analyses.

Online supplementary table 1 shows the statistical significance of annual trends in work disability before and after an IHD event stratified by sex in each diagnostic category. The trend in work disability among both men and women was increasing before the event due to diseases of the circulatory system (men: RR 2.09; 95\% CI 1.93 to 2.25; women: RR 1.99; 95\% CI 1.77 to 2.23), mental (men: RR 1.43 ; $95 \%$ CI 1.35 to 1.51 ; women: RR 1.35 ; $95 \%$ CI 1.25 to 1.45 ) and musculoskeletal (men: RR $1.38 ; 95 \%$ CI $1.32,1.45$; women RR $1.30,95 \%$ CI 1.23 to 1.36 ) disorders. After the event, the trend was decreasing regarding 


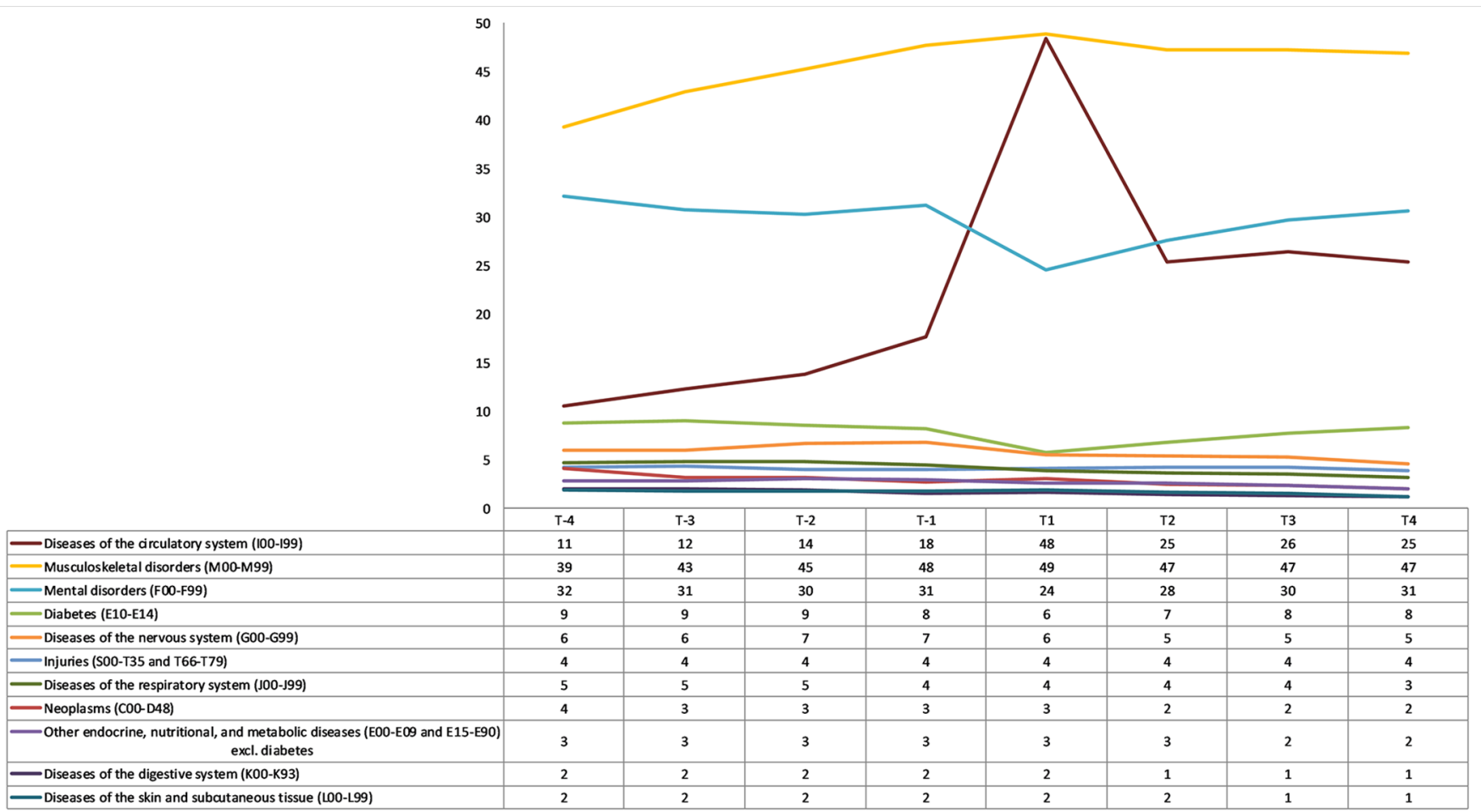

Figure 2 Mean annual number of days of work disability before and after an ischaemic heart disease event among women $(n=5951)$ by the International Classification of Diseases, 10th revision diagnostic category.

diseases of the circulatory system (men RR $0.33 ; 95 \%$ CI 0.31 to 0.35 ; women RR 0.42 ; $95 \%$ CI 0.39 to 0.47 ) and musculoskeletal disorders (men RR 0.92; 95\% CI 0.89 to 0.96 ; women RR 0.95 ; $95 \%$ CI 0.91 to 0.99 ).

Figure 3 shows the mean annual number of work disability days in the four most common diagnostic groups before and after an IHD event adjusted for confounding by demographic and socioeconomic factors and medical treatment procedures among men and women. In figure $3 \mathrm{~A}$, work disability due to diseases of the circulatory system increased even more sharply 1-year postevent among both sexes after adjustments. Among men, adjusted work disability days due to circulatory diseases increased from 12 to 60; a 5.2-fold increase in the last pre-event year compared with first postevent year. The corresponding increase was 4.4-fold among women (from 14 to 62 days). The decrease from the first to second postevent year was 3.2-fold (from 60 to 19 days) among men and 2.7-fold (from 62 to 23 days) among women. Among women, mean days of work disability due to diseases of the circulatory system remained at a higher level than those among men during the postevent years (postevent difference between women and men was about 4 days). As for the other diagnostic groups of musculoskeletal and mental disorders and diabetes (figure 3B-D), the trends were moderately increasing throughout the follow-up, with women consistently having more work disability days than men. IHD event did not impact the trend in other diagnostic groups.

Table 2 demonstrates comparisons of the postevent period to the pre-event period as regard the risk of diagnosis-specific work disability among men and women. The risk of work disability increased after the event for disability due to diseases of the circulatory system, musculoskeletal disorders, mental disorders and diabetes among both sexes. We observed a statistically significant interaction of sex and year regarding work disability due to diseases of the circulatory system. Thus, while the absolute mean number of work disability days due to diseases of the circulatory system was higher among women than men during the postevent years, the relative increase in the risk of work disability was slightly higher among men than among women. This is due to a sharper increase in the first postevent year among men, illustrated in figure 3 .

\section{DISCUSSION}

This longitudinal study of all working-age individuals in Sweden who suffered their first IHD event in 2006-2008 provided novel information on work disability diagnoses before and after an IHD event. We showed that before an IHD event, mental and musculoskeletal disorders were the most prevalent diagnoses, corresponding to those observed among the general population. ${ }^{23}$ The high prevalence of musculoskeletal disorder-related work disability after an IHD event, particularly among women, was explained by permanent work disability (disability pension) before the event. A total of $41 \%$ of women who had an IHD event were already permanently disabled from work prior to the IHD event. The corresponding figure for men was $22 \%$. These percentages correspond to those previously reported 


\section{(a) Cardiovascular}

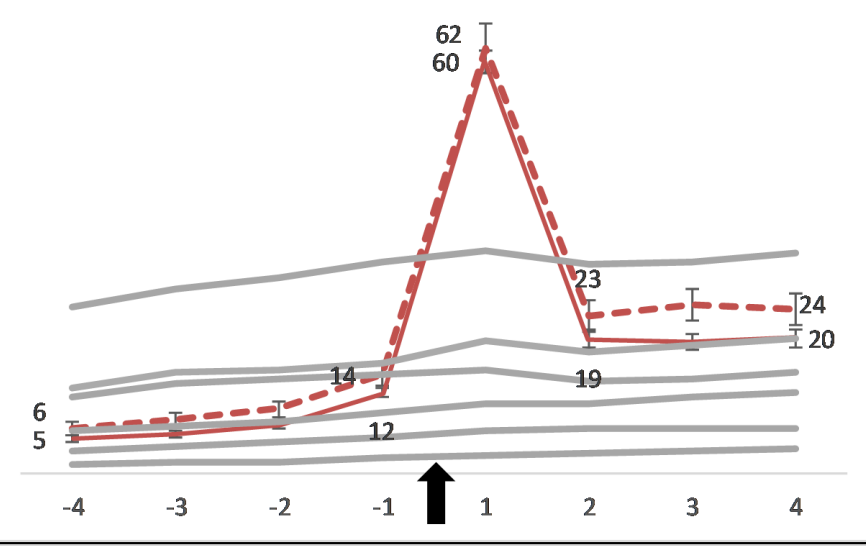

(c) Mental

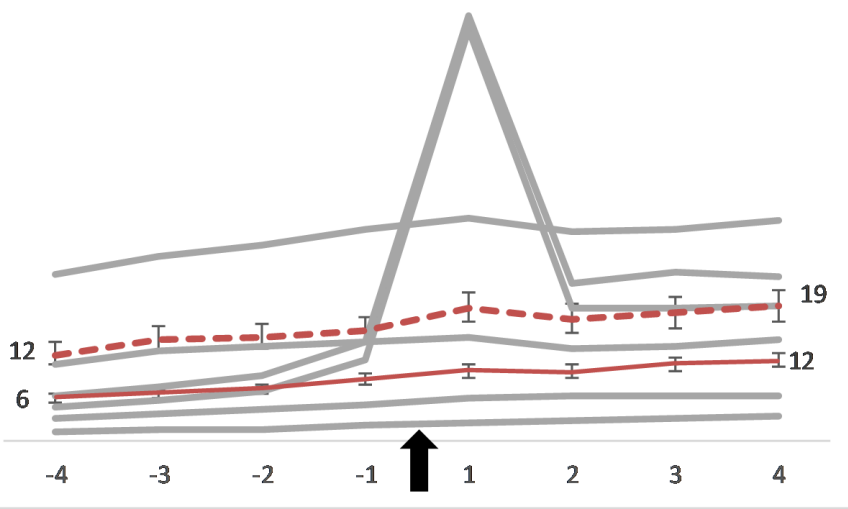

(b) Musculoskeletal

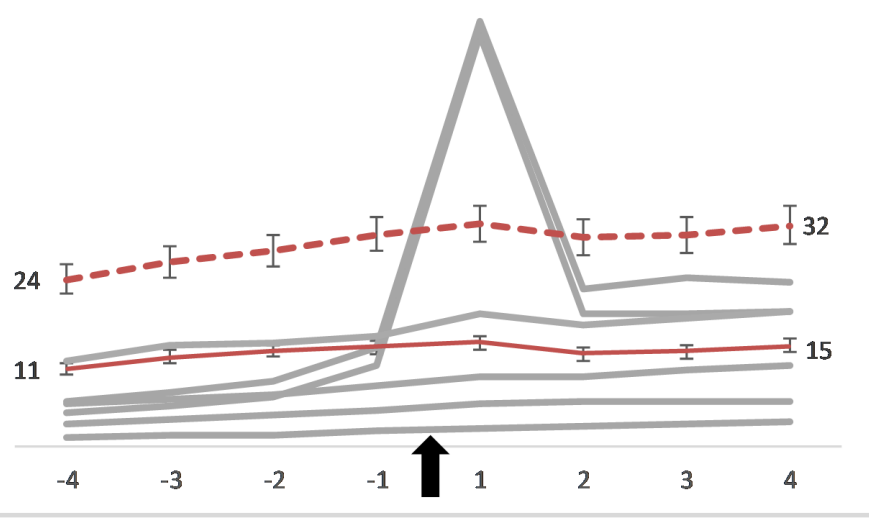

(d) Diabetes

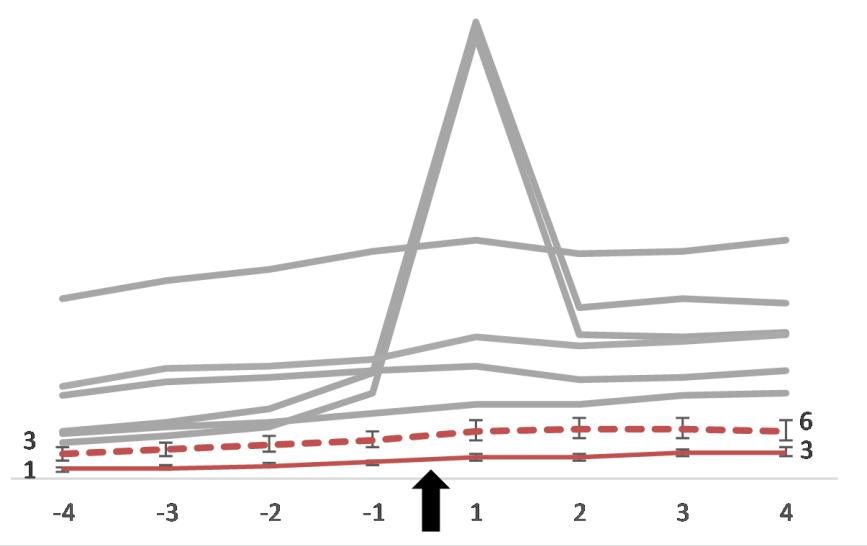

Figure 3 Adjusted mean annual number of days of work disability in the four most common diagnostic groups before and after an ischaemic heart disease (IHD) event among men and women. Error bars indicate 95\% Cls. Models are adjusted for age, education, type of living area, family situation, birth country, economic activity and medical treatment procedures for IHD. Women are marked with dashed line, men with red line. Grey lines mark work disability trends in other diagnostic group. Arrow indicates the event time.

in Finland ${ }^{24}$ and Sweden. ${ }^{12}$ After we excluded those who were permanently disabled from work prior to the event, diseases of the circulatory system were the most prevalent diagnosis of work disability after an IHD event, followed by mental and musculoskeletal disorders among both men and women. This corresponds to two previous studies on diagnoses for disability pensions after coronary interventions in Finland. ${ }^{725}$

Work disability due to diseases of the circulatory system increased considerably a year after an IHD event among both sexes, but this increase was slightly stronger among men. Work disability due to diseases of the circulatory system decreased to one-third from the first to the second postevent year. The end of work disability compensation can be viewed as a return to economic activity. In previous studies, $86 \%$ of patients with acute myocardial infarction returned to work in 1 year, ${ }^{26} 65 \%$ of patients with acute coronary syndrome were working 5 years after diagnosis ${ }^{11}$ and $32 \%$ were on disability pension 5 years after a coronary revascularisation procedure. ${ }^{12}$ The trend in work disability among general population was stable during roughly the same time period. ${ }^{27}$

Our findings correspond to previous research on IHD comorbidity and the risk of work disability, which has linked musculoskeletal-related, mental-related and diabetes-related comorbidity to a higher risk of work disability among people with IHD. ${ }^{10-131828}$ Our results do not indicate that comorbidity-related work disability increases due to an IHD event, but rather that pre-existing musculoskeletal and mental comorbidity may contribute to work disability after the event, as also suggested by recent case-control study. ${ }^{29}$ While the risk of mental-related and musculoskeletal-related work disability was higher after than before the event, the increase in work disability due to these diagnoses was rather stable throughout the follow-up, without an increase at the time of an IHD event as noted regarding the diagnostic group of diseases of the circulatory system.

We observed high levels of work disability due to musculoskeletal disorders before an IHD event, especially among women. Of musculoskeletal disorders, previous research 
Table 2 RRs with 95\% Cls comparing risk of work disability after an IHD event to before in men and women

\begin{tabular}{|c|c|c|c|}
\hline $\begin{array}{l}\text { Diagnosis of } \\
\text { work disability }\end{array}$ & $\begin{array}{l}\text { Interaction with } \\
\text { time }\end{array}$ & $\mathbf{R R}^{*}$ & $95 \% \mathrm{Cl}$ \\
\hline \multicolumn{4}{|c|}{$\begin{array}{l}\text { Diseases of the } \\
\text { circulatory system }\end{array}$} \\
\hline Men & & 2.49 & 2.36 to 2.62 \\
\hline Women & & 2.29 & 2.12 to 2.49 \\
\hline Sex×year & $\chi^{2}=33.0, p<0.001$ & & \\
\hline \multicolumn{4}{|l|}{$\begin{array}{l}\text { Musculoskeletal } \\
\text { disorder }\end{array}$} \\
\hline Men & & 1.09 & 1.04 to 1.14 \\
\hline Women & & 1.14 & 1.08 to 1.21 \\
\hline Sex×year & $\chi^{2}=6.75, p=0.46$ & & \\
\hline \multicolumn{4}{|l|}{ Mental disorder } \\
\hline Men & & 1.47 & 1.37 to 1.56 \\
\hline Women & & 1.29 & 1.18 to 1.41 \\
\hline Sex×year & $\chi^{2}=13.1, p=0.07$ & & \\
\hline \multicolumn{4}{|l|}{ Diabetes } \\
\hline Men & & 2.01 & 1.77 to 2.27 \\
\hline Women & & 1.59 & 1.37 to 1.84 \\
\hline Sex×year & $\chi^{2}=1.13, p=0.13$ & & \\
\hline
\end{tabular}

${ }^{*} \mathrm{RR}$ for work disability comparing different time points. Years $1,2,3$ and 4 are contrasted to years $-4,-3,-2$ and -1 . Models are adjusted for age, sex, education, type of living area, family situation, birth country, economic activity and medical treatment procedures for IHD.

$\mathrm{IHD}$, ischaemic heart disease; $\mathrm{RR}$, rate ratio.

has established a link between rheumatoid arthritis and a higher risk of IHD-related morbidity and mortality. ${ }^{30-32}$ Chronic inflammation may be the mechanism linking musculoskeletal disorders in general to IHD. The link between musculoskeletal disorders and IHD could also be due to uncontrolled confounding: the traditional risk factors of IHD, namely high body mass index, smoking, high alcohol consumption and lack of physical activity, may be over-represented among people with musculoskeletal disorders, and may be reasons for why they suffer more from IHD. ${ }^{334}$ This, however, warrants more research, as our register data did not include lifestyle-related information.

Mental comorbidity was also rather prevalent both before and after the IHD event, and was the third most common diagnostic group. Mental disorders combined with IHD may cause poor medication adherence, ${ }^{35} 36$ which may worsen the prognosis of IHD and future work capacity. The most prevalent mental diagnosis, depression, has also been associated with a higher risk of cardiovascular events, which corresponds to our findings regarding high levels of mental disorder-related work disability before the IHD event. ${ }^{37-39}$ Some evidence exists that IHD might predispose people to depression and other common mental disorders later in life, ${ }^{14} 15$ and depressed mood measured after admission has been linked to slower return to work after acute coronary syndrome. ${ }^{40}$

People with diabetes have a worse prognosis after revascularisation than people without diabetes, ${ }^{41}{ }^{42}$ and diabetes itself also increases the risk of work disability. ${ }^{434}$ However, the most common diagnoses of work disability among people with diabetes are mental, musculoskeletal and cardiovascular, ${ }^{45}$ suggesting that diabetes combined with IHD is reflected in work disability due to diseases of the circulatory system rather than IHD being associated with worse prognosis of diabetes and diabetes-related work disability.

After an IHD event, work disability was more prevalent among women than among men, an observation also reported previously. ${ }^{18}{ }^{26}$ We extended the previous research by examining the diagnoses for work disability, and found a consistent gender gradient across cardiovascular-related, musculoskeletal-related, mental-related and diabetes-related diagnoses. However, no diagnosis-specific sex difference was observed. Higher mortality and worse cardiovascular outcomes are observed in women with IHD than among men, especially among younger patients $(<65$ years and particularly $<55$ years). This is partially attributed to the incomplete use of secondary prevention treatment regimens, ${ }^{16}$ but may also related to physician who tend to underestimate cardiovascular risk in women, which may delay the diagnosis. ${ }^{17}$ Compared with men, women are at increased risk of adverse outcomes after coronary artery bypass graft and percutaneous coronary interventions. ${ }^{17}$ They are also at increased risk of bleeding from medical therapies used in acute coronary syndrome and the use of femoral access for percutaneous coronary intervention. ${ }^{16}$ In this study, the sex difference was not explained by the sociodemographic characteristics or treatment procedures investigated.

\section{Strengths and limitations}

The major strength of this study was the large population-based cohort data with reliable register-based measurements of high coverage and specificity, ${ }^{46}$ and no loss to follow-up. While there are no studies about the quality of register-based sickness absence data in Sweden, Danish registers have proven a valid measure. ${ }^{47}$ Generally, register-based data on sickness absence can be viewed as a golden standard compared with self-report data. However, it should be noted that the first 14 days of sick leave spells were not recorded in our data. These short-term sickness absences are most likely due to respiratory diseases, gastroenteritis and headache/migraine, ${ }^{48}$ and less likely due to circulatory diseases, mental or musculoskeletal disorders, which were the main diagnostic groups among people with IHD. We extended previous research by examining the diagnosis of work disability before and after an IHD event.

While we could include many confounders related to sociodemographic characteristics and treatment procedures, some residual confounding remained. We had no information on traditional cardiovascular risk factors or psychosocial work environment factors, which may possibly have explained the observed gender difference in work disability. 
Patients without hypertension had a higher likelihood of return to work than patients with hypertension. ${ }^{26}$ However, smoking, obesity, social support or financial strain have not been found to be significant predictors of return to work after acute myocardial infarction. ${ }^{26}$ Coronary artery bypass graft, percutaneous coronary intervention or other coronary surgeries associated with the IHD event were treated as a proxy for event severity. However, patients with most severe presentations are often treated conservatively because they are frail, have several impeditive comorbidities or have a severe coronary artery disease not amenable to revascularisation. Thus, more research on the impact of event severity is needed to make definite conclusions. Moreover, we had no information on quality and outcome of postevent care. In a previous German study, men were more likely to enrol in disease management programme than women after IHD event. ${ }^{49}$ Finally, it is possible that people have moved their place of residence or changed their marital status after the IHD event. However, we see this having minor impact on the results and subsequent conclusions.

\section{CONCLUSIONS}

We found that an IHD event was related to a sharp increase in work disability due to circulatory diseases, especially among men and particularly in the first postevent year. Women had more IHD-related and comorbidity-related work disability after the event than men. Occupational healthcare and other healthcare professionals, who monitor sickness absence, may benefit from such knowledge.

Contributors JE, TL, MV, EM-R and KA contributed to conception and design. $\mathrm{JE}$ analysed the data and drafted the manuscript. MV, TL, EF, EM-R, EL and KA contributed to interpretation of the results and critically revised the manuscript. All gave final approval and agree to be accountable for all aspects ensuring integrity and accuracy.

Funding This work was supported by Forskningsrådet om Hälsa, Arbetsliv och Välfärd (The Swedish Research Council for Health, Working Life and Welfare). JE, MV and TL were supported by Suomen Akatemia (Academy of Finland), project numbers 258598, 292824, 287488, 294096.

Competing interests None declared.

Patient consent Not required.

Ethics approval The project was approved by the Regional Ethical Review Board, Stockholm, Sweden.

Provenance and peer review Not commissioned; externally peer reviewed.

Data sharing statement № additional data are available.

Open Access This is an Open Access article distributed in accordance with the Creative Commons Attribution Non Commercial (CC BY-NC 4.0) license, which permits others to distribute, remix, adapt, build upon this work non-commercially, and license their derivative works on different terms, provided the original work is properly cited and the use is non-commercial. See: http://creativecommons.org/ licenses/by-nc/4.0/

(C) Article author(s) (or their employer(s) unless otherwise stated in the text of the article) 2018. All rights reserved. No commercial use is permitted unless otherwise expressly granted.

\section{REFERENCES}

1. Lerner DJ, Kannel WB. Patterns of coronary heart disease morbidity and mortality in the sexes: a 26-year follow-up of the Framingham population. Am Heart J 1986;111:383-90.
2. Who is at risk for coronary heart disease?: National Institutes of Health, National heart, Lung and Blood Institute. 2016 https://www. nhlbi.nih.gov/health/health-topics/topics/cad/atrisk (accessed 21 Mar 2017).

3. Johnston SS, Curkendall S, Makenbaeva D, et al. The direct and indirect cost burden of acute coronary syndrome. $J$ Occup Environ Med 2011;53:2-7.

4. Zhao Z, Winget M. Economic burden of illness of acute coronary syndromes: medical and productivity costs. BMC Health Serv Res 2011;11:35.

5. Song X, Quek RG, Gandra SR, et al. Productivity loss and indirect costs associated with cardiovascular events and related clinical procedures. BMC Health Serv Res 2015;15:245.

6. Banefelt J, Hallberg S, Fox KM, et al. Work productivity loss and indirect costs associated with new cardiovascular events in highrisk patients with hyperlipidemia: estimates from population-based register data in Sweden. Eur J Health Econ 2016;17:1117-24.

7. Lautamäki A, Gunn JM, Airaksinen KEJ, et al. Permanent work disability in patients $\leq 50$ years old after percutaneous coronary intervention and coronary artery bypass grafting (the CRAGS study). Eur Heart J Qual Care Clin Outcomes 2017;3:101-6 https:// doi.org/.

8. Menzin J, Wygant G, Hauch O, et al. One-year costs of ischemic heart disease among patients with acute coronary syndromes: findings from a multi-employer claims database. Curr Med Res Opin 2008;24:461-8.

9. Tarride JE, Lim M, DesMeules M, et al. A review of the cost of cardiovascular disease. Can J Cardiol 2009;25:e195-202.

10. Detaille SI, Heerkens YF, Engels JA, et al. Common prognostic factors of work disability among employees with a chronic somatic disease: a systematic review of cohort studies. Scand J Work Environ Health 2009;35:261-81.

11. Osler $\mathrm{M}, \mathrm{Mårtensson} \mathrm{S}$, Prescott $\mathrm{E}$, et al. Impact of gender, comorbidity and social factors on labour market affiliation after first admission for acute coronary syndrome. A cohort study of Danish patients 2001-2009. PLoS One 2014;9:e86758.

12. Zetterström K, Vaez M, Alexanderson $\mathrm{K}$, et al. Disability pension after coronary revascularization: a prospective nationwide register-based Swedish cohort study. Eur J Prev Cardiol 2015;22:304-11.

13. Mittendorfer-Rutz E, Ivert $T$, Vaez $M$, et al. Synergistic effect between ischaemic heart disease and common mental disorders and the risk of premature exit from the labour market: a nationwide register based study from Sweden. Eur Heart J 2018;39:578-585.

14. Valkanova V, Ebmeier KP. Vascular risk factors and depression in later life: a systematic review and meta-analysis. Biol Psychiatry 2013;73:406-13.

15. Virtanen M, Elovainio M, Josefsson $\mathrm{K}$, et al. Coronary heart disease and risk factors as predictors of trajectories of psychological distress from midlife to old age. Heart 2017;103.

16. Sanghavi M, Gulati M. Sex differences in the pathophysiology, treatment, and outcomes in IHD. Curr Atheroscler Rep 2015;17:511.

17. Vaccarino V, Badimon L, Corti R, et al. Presentation, management, and outcomes of ischaemic heart disease in women. Nat Rev Cardiol 2013;10:508-18.

18. Voss M, Ivert T, Pehrsson K, et al. Sickness absence following coronary revascularisation. A national study of women and men of working age in Sweden 1994-2006. PLoS One 2012;7:e40952.

19. Meyer S, Brouwers FP, Voors AA, et al. Sex differences in new-onset heart failure. Clin Res Cardiol 2015;104:342-50.

20. Ferrie JE, Vahtera J, Kivimäki M, et al. Diagnosis-specific sickness absence and all-cause mortality in the GAZEL study. J Epidemiol Community Health 2009;63:50-5.

21. Summary of Population Statistics 1960-2016: Statistics Sweden. 2017 http://www.scb.se/en/finding-statistics/statistics-by-subjectarea/population/population-composition/population-statistics/pong/ tables-and-graphs/yearly-statistics-the-whole-country/summary-ofpopulation-statistics/.

22. NOMESCO Classification of Surgical Procedures: Nordic MedicoStatistical Committee (NOMESCO). 2011.

23. OECD. Sickness, disability and work: breaking the barriers. A synthesis of findings across OECD Countries. Paris: OECD Publishing, 2010.

24. Hämäläinen $\mathrm{H}$, Mäki J, Virta $L$, et al. Return to work after first myocardial infarction in 1991-1996 in Finland. Eur J Public Health 2004;14:350-3.

25. Gunn J, Kiviniemi T, Biancari F, et al. Predictors of permanent work disability among $\leq 50$-year-old patients undergoing percutaneous coronary intervention. Scand J Work Environ Health 2015;41:460-6.

26. Dreyer RP, Xu X, Zhang W, et al. Return to work after acute myocardial infarction: comparison between Young women and men. Circ Cardiovasc Qual Outcomes 2016;9:S45-52. 
27. Virtanen M, Ervasti J, Mittendorfer-Rutz E, et al. Work disability before and after a major cardiovascular event: a ten-year study using nationwide medical and insurance registers. Sci Rep 2017;7:1142.

28. Jespersen L, Abildstrøm SZ, Hvelplund A, et al. Symptoms of angina pectoris increase the probability of disability pension and premature exit from the workforce even in the absence of obstructive coronary artery disease. Eur Heart J 2013;34:3294-303.

29. Wang M, Vaez M, Dorner TE, et al. Trajectories and characteristics of work disability before and after acute myocardial infarction. Heart 2018;104.

30. Hollan I, Meroni PL, Ahearn JM, et al. Cardiovascular disease in autoimmune rheumatic diseases. Autoimmun Rev 2013;12:1004-15.

31. Hollan I, Dessein PH, Ronda N, et al. Prevention of cardiovascular disease in rheumatoid arthritis. Autoimmun Rev 2015;14:952-69.

32. Houri Levi E, Watad A, Whitby A, et al. Coexistence of ischemic heart disease and rheumatoid arthritis patients-A case control study. Autoimmun Rev 2016;15:393-6.

33. Boyer JF, Gourraud PA, Cantagrel A, et al. Traditional cardiovascular risk factors in rheumatoid arthritis: a meta-analysis. Joint Bone Spine 2011;78:179-83.

34. Liao KP, Solomon DH. Traditional cardiovascular risk factors, inflammation and cardiovascular risk in rheumatoid arthritis. Rheumatology 2013;52:45-52.

35. May HT, Sheng X, Catinella AP, et al. Antilipidemic adherence post-coronary artery disease diagnosis among those with and without an ICD-9 diagnosis of depression. J Psychosom Res 2010;69:169-74.

36. Son YJ, Kim SH, Park JH. Role of depressive symptoms and self-efficacy of medication adherence in Korean patients after successful percutaneous coronary intervention. Int J Nurs Pract 2014;20:564-72

37. Huang CQ, Dong BR, Lu ZC, Zc L, et al. Chronic diseases and risk for depression in old age: a meta-analysis of published literature. Ageing Res Rev 2010;9:131-41.

38. Hare DL, Toukhsati SR, Johansson P, et al. Depression and cardiovascular disease: a clinical review. Eur Heart $J$ 2014;35:1365-72.
39. Seldenrijk A, Vogelzangs N, Batelaan NM, et al. Depression, anxiety and 6-year risk of cardiovascular disease. J Psychosom Res 2015;78:123-9.

40. Bhattacharyya MR, Perkins-Porras L, Whitehead DL, et al. Psychological and clinical predictors of return to work after acute coronary syndrome. Eur Heart J 2007;28:160-5.

41. Banning AP, Westaby S, Morice MC, et al. Diabetic and nondiabetic patients with left main and/or 3-vessel coronary artery disease: comparison of outcomes with cardiac surgery and paclitaxel-eluting stents. J Am Coll Cardiol 2010;55:1067-75.

42. Gilbert J, Raboud J, Zinman B. Meta-analysis of the effect of diabetes on restenosis rates among patients receiving coronary angioplasty stenting. Diabetes Care 2004;27:990-4.

43. Herquelot $E$, Guéguen A, Bonenfant $S$, et al. Impact of diabetes on work cessation: data from the GAZEL cohort study. Diabetes Care 2011;34:1344-9.

44. Ervasti J, Virtanen M, Lallukka T, et al. Contribution of comorbid conditions to the association between diabetes and disability pensions: a population-based nationwide cohort study. Scand $J$ Work Environ Health 2016;42:209-16.

45. Virtanen M, Ervasti J, Mittendorfer-Rutz E, et al. Trends of diagnosisspecific work disability after newly diagnosed diabetes: a 4-year nationwide prospective cohort study. Diabetes Care 2015;38:1883-90.

46. Ludvigsson JF, Andersson E, Ekbom A, et al. External review and validation of the Swedish national inpatient register. BMC Public Health 2011;11:450.

47. Stapelfeldt CM, Jensen C, Andersen NT, et al. Validation of sick leave measures: self-reported sick leave and sickness benefit data from a Danish national register compared to multiple workplace-registered sick leave spells in a Danish municipality. BMC Public Health 2012;12:661.

48. Feeney A, North F, Head J, et al. Socioeconomic and sex differentials in reason for sickness absence from the Whitehall II Study. Occup Environ Med 1998:55:91-8.

49. Bozorgmehr K, Maier W, Brenner $\mathrm{H}$, et al. Social disparities in Disease Management Programmes for coronary heart disease in Germany: a cross-classified multilevel analysis. J Epidemiol Community Health 2015;69:1091-101. 